\title{
Fisiopatologia das entesopatias: aspectos mecânicos e inflamatórios (axial e periférico)
}

\author{
André Marun Lyrio ${ }^{1}$, Rodrigo Luppino ${ }^{2}$ \\ DOI: https://doi.org/10.46833/reumatologiasp.2020.19.4.18-20
}

\begin{abstract}
Resumo Queixas relacionadas com a entesopatia são frequentes na prática clínica, sendo na maioria das vezes de origem mecânica, decorrentes de distúrbios biomecânicos e metabólicos. Na reumatologia, as espondiloartrites (EpAs) são as principais responsáveis pelos distúrbios entesiais de origem inflamatória, sendo postulado que esses distúrbios são os responsáveis por iniciar e perpetuar o processo inflamatório sistêmico, com papel central em sua fisiopatologia. O início da agressão à êntese parece ser o mesmo em ambos os cenários, o estresse biomecânico. Porém, a resposta do organismo define como o processo irá se desenvolver e resolver, seja em poucas semanas e com reparação tecidual, seja com cronificação ou resolução incompleta do processo levando à ossificação e anquilose. Portanto, é fundamental que a mecanobiologia dos tendões e ligamentos seja compreendida, bem como a fisiopatologia das espondiloartrites. Nesta revisão, descrevemos detalhadamente as principais bases fisiopatológicas para as lesões entesíticas mecânicas e inflamatórias, axiais e periféricas.
\end{abstract}

Unitermos Êntese. Entesopatia. Estresse mecânico. Fisiopatologia. Espondiloartrites.

A inflamação da êntese é uma lesão muito frequentemente presente nas espondiloartrites e desempenha papel importante na fisiopatologia desta doença ${ }^{1}$.

O processo inflamatório desta região de transição tendão/ osso e ligamento/osso pode estar presente também em decorrência de lesões traumáticas, principalmente traumas decorrentes de alterações biomecânicas permanentes ou de longa duração ${ }^{1}$.

Quando falamos em lesões entesíticas biomecânicas, a etiologia é multifatorial, com fatores intrínsecos e extrínsecos desempenhando importante papel na fisiopatologia. Esses fatores são variáveis, dependendo do local da lesão e do tipo da lesão esportiva ou em pessoas sedentárias ${ }^{1}$.

Dentre os fatores intrínsecos envolvidos na fisiopatologia da entesite de origem mecânica podemos citar o diabetes mellitus, idade avançada, aumento no IMC (sobrepeso/obesidade), diminuição da força muscular, lesões prévias, exposição a medicamentos (por exemplo glicocorticoides e quinolonas) e distúrbios biomecânicos ${ }^{1}$.

Dentre os fatores extrínsecos envolvidos na fisiopatologia da entesite de origem mecânica podemos citar os erros de trei-
1. Professor de Reumatologia da Pontifícia Universidade Católica de Campinas, Campinas-SP. Membro da Comissão de Artrite Psoriásica da Sociedade Brasileira de Reumatologia.

2. Médico assistente do Hospital das Clínicas da Faculdade de Medicina de Ribeirão Preto da Universidade de São Paulo, Ribeirão PretoSP. Responsável pelo Ambulatório de Espondiloartrites. Membro da Comissão de Artrite Psoriásica da Sociedade Brasileira de Reumatologia.

Correspondência: Dr. André Marun Lyrio, e-mail: andre_lyrio@yahoo.com.br; Dr. Rodrigo Luppino, e-mail: rodluppinoassad@gmail.com.
Como citar este artigo: Lyrio AM, Luppino R. Fisiopatologia das entesopatias: aspectos mecânicos e inflamatórios (axial e periférico). Rev Paul Reumatol. 2020 out-dez;19(4):18-20. DOI: https://doi.org/10.46833/reumatologiasp.2020.19.4.18-20.

Os autores não contaram com apoio financeiro.

Os autores declaram não ter interesses associativos, comerciais, de propriedade ou financeiros que representem conflito de interesse nos produtos e empresas descritos neste artigo. 
namento, seja falha no programa do treino, carga, piso ou calçado utilizado ${ }^{1}$.

A entesite pode, portanto, resultar de sobrecarga mecânica repetida, como a que ocorre durante atividades esportivas, em indivíduos saudáveis. Como exemplos de lesões entesíticas biomecânicas temos a tendinite do tendão do calcâneo, que se mostrou a lesão mais frequente entre corredores mais experientes ${ }^{2}$, e as epicondilites, tanto lateral, também chamada de "cotovelo de tenista", quanto medial, "cotovelo de golfista". Nestes casos, a entesite geralmente afeta apenas uma êntese, envolve também o corpo do tendão e geralmente se resolve espontaneamente ${ }^{6}$.

A entesite, cuja origem deriva de um processo inflamatório mediado por células do sistema imune, é uma condição muito sugestiva de espondiloartrites (EpAs) que inclui a espondilite anquilosante, artrite psoriásica, espondiloartrite enteropática, artrite reativa e a espondiloartrite indiferenciada, apresentando algumas características fisiopatológicas distintas dependendo da região em que esta entesite esteja presente, seja ela axial ou periférica ${ }^{3}$.

A razão pela qual os pacientes com EpAs apresentam as entesites não está totalmente esclarecida e não há evidências conclusivas de que o processo fundamental seja diferente das entesites resultantes de sobrecarga mecânica ${ }^{6}$.

Uma das hipóteses aventadas é a de que os pacientes com EpAs apresentem maior risco de inflamação, mesmo com pouca ou nenhuma força mecânica, assemelhando-se a uma reação que ocorre na psoríase, fenômeno de Koebner, quando ocorre reação inflamatória exagerada e persistente da pele submetida a irritação mecânica cutânea.

As possíveis explicações incluem fatores genéticos, como genes MHC classe I e polimorfismos em IL23R (que codifica o receptor de IL-23), que levam ao aumento da ativação da resposta imune ${ }^{7}$, e à possibilidade de função de barreira epitelial alterada, devido à concomitante psoríase clínica ou subclínica (na EpA) e colite (na EpA), que resultam em maior exposição ao estresse microbiano e respostas imunológicas prolongadas ${ }^{8}$.

As observações clínicas sugerem que o estresse mecânico seja um fator central na indução da entesite. Assim, a entesite afeta principalmente os membros inferiores, que estão expostos a forças mecânicas superiores às dos membros superiores. Consoante a esse conceito, a descarga mecânica em camundongos é suficiente para reduzir a entesite do tendão de Aquiles .

Uma êntese normal é desprovida de vascularização, porém, na entesite, ela está presente precocemente e é importante, conjuntamente com a prostaglandina E2 que provoca vasodilatação, por facilitar a migração de neutrófilos da medular óssea. Os neutrófilos migrados liberam proteases e espécies reativas de oxigênio. A prostaglandina E2, além da vasodilatação, provoca a liberação de IL17 dos linfócitos T residentes nas ênteses 5 . Desta forma, a entesite parece ser desencadeada predominantemente por uma resposta imune inata, sem a ativação das células B, as reações foliculares e a formação de autoanticorpos?.

O papel da PGE2 na entesite é apoiado pela notável resposta da entesite axial e periférica ao tratamento com AINEs. A produção local de PGE2 pode permitir uma resposta rápida de estresse à sobrecarga mecânica ou outros gatilhos nas ênteses. Células mesenquimais residentes, por exemplo, expressam prostaglandina G/H sintase 2 induzível (também conhecida como ciclo-oxigenase 2), o que explica a produção sítio-específica de PGE2, que é o principal produto enzimático das ciclo-oxigenases ${ }^{10}$.

As células residentes das ênteses, dentre elas os macrófagos, células NK, células T, células relacionadas com o ácido retinoico $\left(\mathrm{ROR}-\mathrm{t}^{\mathrm{t}}\right)$, são ativadas pelas IL23 produzidas pelas células dendríticas. Essas células residentes passam então a produzir interleucinas (as mais importantes são as IL-6, IL-17, IL-22), e citocinas (TNF), que aumenta a infiltração por polimorfonucleares na região ${ }^{12}$.

Ainda não está claro se outras células que expressam IL-23R povoam os sítios entesais. Algumas evidências sugerem que as células linfoides inatas (ILCs) são candidatas interessantes a esse respeito ${ }^{13}$. Essas células não expressam um receptor de células T, mas compartilham as vias de ativação de citocinas com linhagens de células T específicas. Os ILCs do tipo 3, por exemplo, expressam IL-23R, produzem IL-17A e podem ser encontrados em ênteses humanas normais ${ }^{14}$. 0 papel funcional dessas células na entesite, entretanto, ainda precisa ser determinado.

A proximidade desse tecido enteseal inflamado com a medular óssea e a migração de células desta região levam ao edema do osso subcondral (osteíte) com a formação de erosões ósseas. O processo inflamatório extra-articular (entesites e peritendinites) estende-se também para o ambiente intra-articular, levando à sinovite ${ }^{15}$.

Quanto à entesite axial, fisiopatologicamente encontramos células residentes entesiais diferentes de todas as outras do organismo, dentre elas um linfócito $\mathrm{T} \gamma \delta$, que tem a capacidade de produzir IL17 com estímulo de estresse biomecânico e também com o estímulo da IL233.

Outra importante diferença da entesite de origem mecânica para a entesite de origem inflamatória é que esta última tem a capacidade de estimular em seu microambiente inflamatório diferentes mecanismos ainda não completamente elucidados de osteoproliferação com consequente neoformação óssea exuberante e ossificação da região, podendo levar à anquilose quando no ambiente axial e neoformações ósseas em regiões entesíticas periféricas. Dentre os mecanismos postulados para esse processo de ossificação entesial estão a hiperexpressão de receptores cálcio sensíveis (CaSR), vários tipos de fator de crescimento osteogênico e proteínas da família $\mathrm{Wnt}^{4}$.

Portanto, é fundamental que a mecanobiologia dos tendões e ligamentos seja compreendida. Conhecimentos nas áreas de biomecânica, biologia celular e imunologia que, quando combinados, proporcionarão uma grande visão sobre doenças musculoesqueléticas de origens aparentemente diversas, como tendionopatias e as EpAs.

O estresse mecânico é um cofator importante que deve ser considerado na avaliação das EpAs, principalmente nas fases iniciais, e as interações com o sistema imunológico aparecem no momento como a base fisiopatológica destas doenças. Contudo, devemos lembrar que a maioria das entesites e tendinopatias é de origem não imunorreumatológica, com componentes mecânico e metabólico preponderantes. 


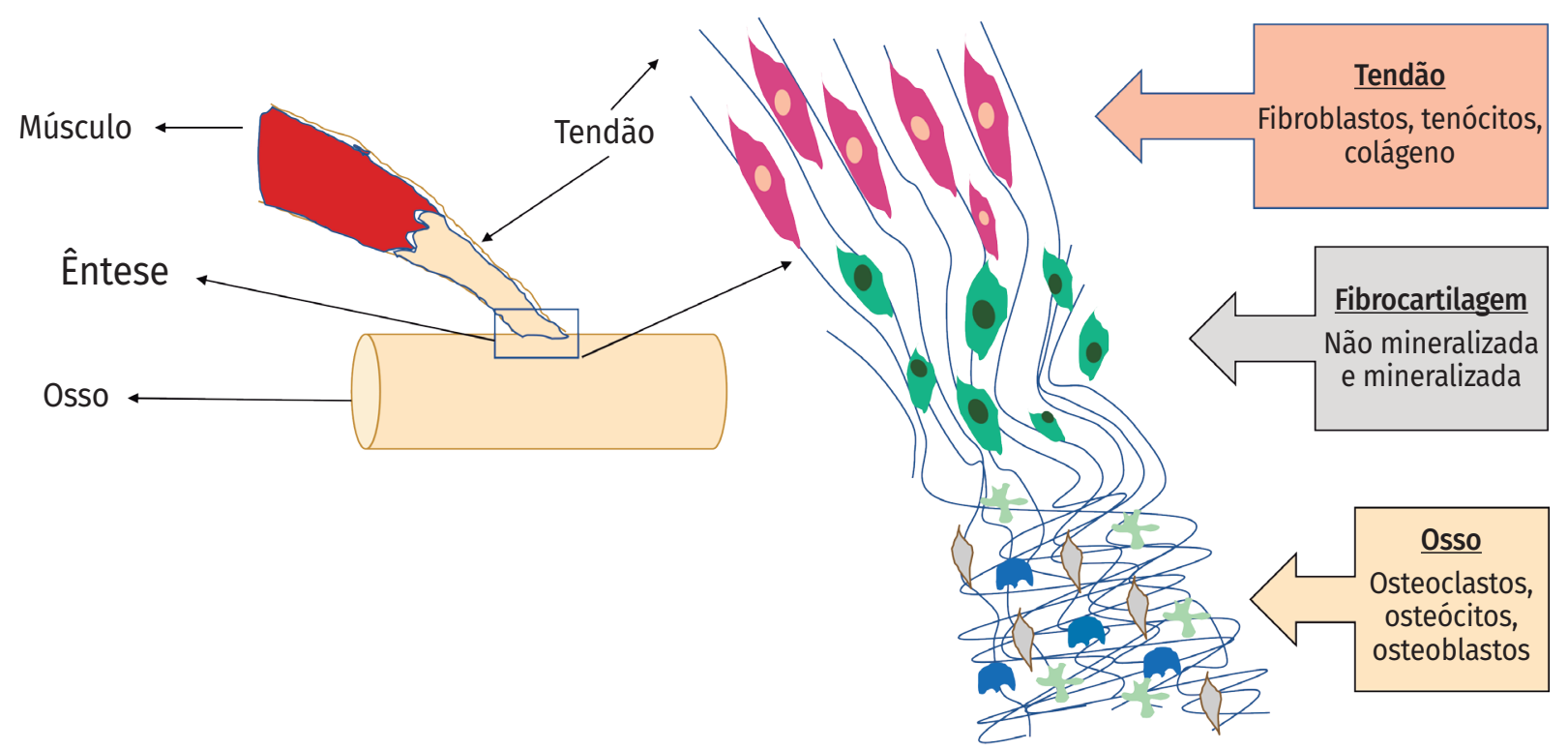

FIGURA 1 Esquema da transição tendão-osso fibrocartilagem.

\section{Referências}

1. Sancho I, Malliaras P, Barton C, Willy RW, Morrissey D. Biomechanical alterations in individuals with Achilles tendinopathy during running and hopping: A systematic review with meta-analysis. Gait Posture. 2019 Sep;73:189-201. Epub 2019 Jul 12. https://doi.org/10.1016/j.gaitpost.2019.07.121.

2. Knobloch K, Yoon U, Vogt PM. Acute and overuse injuries correlated to hours of training in master running athletes. Foot Ankle Int. 2008 Jul;29(7):671-6. https://doi.org/10.3113/FAl.2008.0671.

3. Cuthbert RJ, Watad A, Fragkakis EM, Dunsmuir R, Loughenbury P, Khan A, et al. Evidence that tissue resident human enthesis $y \delta T$-cells can produce IL-17A independently of IL-23R transcript expression. Ann Rheum Dis. 2019;78:1559-65. https://doi.org/10.1136/annrheumdis-2019-215210.

4. Li X, Chen S, Hu Z, Chen D, Wang J, Li Z, et al. Aberrant upregulation of CaSR promotes pathological new bone formation in ankylosing spondylitis. EMBO Mol Med. 2020 Dec 7;12(12):e12109. Epub 2020 Dec 1. https://doi. org/10.15252/emmm.202012109.

5. Szczerkowska-Dobosz A, Krasowska D, Bartosińska J, Stawczyk-Macieja M, Walczak A, Owczarczyk-Saczonek A, et al. Pathogenesis of psoriasis in the "omic" era. Part IV. Epidemiology, genetics, immunopathogenesis, clinical manifestation and treatment of psoriatic arthritis. Postepy Dermatol Alergol. 2020 Oct;37(5):625-634. Epub 2020 Nov 7. https://doi.org/10.5114/ ada.2020.100478.

6. Schett G, Lories RJ, D'Agostino M-A, Elewaut D, Kirkham B, Soriano ER, et al. Enthesitis: from pathophysiology to treatment. Nat Rev Rheumatol. 2017 Nov 21;13(12):731-741. https://doi.org/10.1038/nrrheum.2017.188.

7. McGonagle D, Aydin SZ, Gül A, Mahr A, Direskeneli H. 'MHC-I-opathy' -unified concept for spondyloarthritis and Behçet disease. Nat Rev Rheumatol. 2015 Dec;11(12):731-40. Epub 2015 Nov 3. https://doi.org/10.1038/nrrheum.2015.147.
8. Xavier RJ, Podolsky DK. Unravelling the pathogenesis of inflammatory bowel disease. Nature. 2007 Jul 26;448(7152):427-34. https://doi.org/10.1038/ nature06005.

9. Jacques P, Lambrecht S, Verheugen E, Pauwels E, Kollias G, Armaka M, et al. Proof of concept: enthesitis and new bone formation in spondyloarthritis are driven by mechanical strain and stromal cells. Ann Rheum Dis. 2014 Feb;73(2):437-45. Epub 2013 Aug 6. https://doi.org/10.1136/annrheumdis-2013-203643.

10. Paulissen SMJ, van Hamburg JP, Davelaar N, Asmawidjaja PS, Hazes JMW, Lubberts E. Synovial fibroblasts directly induce Th17 pathogenicity via the cyclooxygenase/prostaglandin E2 pathway, independent of IL-23. J Immunol. 2013 Aug 1;191(3):1364-72. Epub 2013 Jul 1. https://doi.org/10.4049/ jimmunol.1300274.

11. Sherlock JP, Joyce-Shaikh B, Turner SP, Chao C-C, Sathe M, Grein J, et al. IL23 induces spondyloarthropathy by acting on ROR-yt+ $\mathrm{CD}_{3}+\mathrm{CD} 4-\mathrm{CD} 8$ - entheseal resident T cells. Nat Med. 2012 Jul 1;18(7):1069-76. https://doi. org $/ 10.1038 / \mathrm{nm} .2817$.

12. Lories RJ, McInnes IB. Primed for inflammation: enthesis-resident T cells. Nat Med. 2012 Jul 6;18(7):1018-9. https://doi.org/10.1038/nm.2854.

13. Reinhardt A, Yevsa T, Worbs T, Lienenklaus S, Sandrock I, Oberdörfer L, et al. Interleukin-23-Dependent $y / \delta$ T Cells Produce Interleukin-17 and Accumulate in the Enthesis, Aortic Valve, and Ciliary Body in Mice. Arthritis Rheumatol. 2016 Oct;68(10):2476-86. https://doi.org/10.1002/art.39732.

14. Cuthbert RJ, Fragkakis EM, Dunsmuir R, Li Z, Coles M, Marzo-Ortega H, et al. Brief Report: Group 3 Innate Lymphoid Cells in Human Enthesis. Arthritis Rheumatol. 2017 Sep;69(9):1816-1822. Epub 2017 Aug 8. https://doi. org/10.1002/art.40150.

15. Gracey E, Burssens A, Cambré I, Schett G, Lories R, McInnes IB, et al. Tendon and ligament mechanical loading in the pathogenesis of inflammatory arthritis. Nat Rev Rheumatol. 2020 Apr;16(4):193-207. Epub 2020 Feb 20. https://doi.org/10.1038/s41584-019-0364-x. 